\title{
0 poder municipal na federação brasileira: reflexão sobre a autonomia municipal e o federalismo
}

\author{
The municipal power in the brasilian federation: concerns about the \\ municipal autonomy and federalism \\ La autonomía municipal en la federatión brasileña: reflexión sobre la \\ autonomía municipal y federalismo
}

Giovani da Silva Corralo*

\section{Resumo}

O presente artigo tem por objetivo o estudo do poder municipal na federação brasileira, sob o foco da relação entre a autonomia municipal e o federalismo. Longe de se perquirir uma pureza metodológica, inadequada nos dias atuais, prepondera o método dialético na elaboração e no desenvolvimento deste trabalho científico. Para tanto, discorre-se sobre o federalismo e a federação brasileira, teorica e historicamente. Em sequência, perpassa-se a autonomia do município na federação brasileira e a sua consideração como ente federado. Por fim, aborda-se a relação entre a autonomia municipal e o federalismo, tanto numa perspectiva teórica, quanto da facticidade dessa relação na realidade constitucional brasileira. A conclusão apontou a relação entre o federalismo e a autonomia municipal.

Palavras-chave: Autonomia municipal. Federalismo. Federação brasileira.

\section{Introdução}

O estudo do município e do federalismo é essencial para a compreensão do Estado e da Federação brasileira. É com esse objetivo que se propõe o estudo do poder municipal na federação brasileira, a refletir sobre a autonomia municipal e o federalismo. Para essa finalidade, discorre-se sobre o federalismo e as federações, a diferenciar esses fenômenos, teorica e historicamente, sem deixar de observar a Federação brasileira. Em sequência, aborda-se a autonomia do município brasileiro, com base nas cons-

\footnotetext{
Docente do Programa de Pós-Graduação em Direito da UPF. Doutor em História pela PUCRS. Este texto é resultado das atividades de pós-doutoramento realizado na Pontificia Universidad Católica de Chile, de agosto de 2012 a março de 2013, como bolsista Capes.
}

Recebido em 28/10/2014 - Aprovado em 28/10/2014 http://dx.doi.org/10.5335/hdtv.15n.1.5281 
tituições pátrias, a alcançar a Constituição de 1988, a única na contemporaneidade a considerar o município como um ente federado. Compreende-se a autonomia auto-organizatória, política, administrativa, financeira e legislativa dos entes locais. Por fim, analisam-se as relações entre a autonomia municipal e o federalismo, tanto numa perspectiva teórica, quanto na análise da federação brasileira.

O caráter emancipatório e de defesa dos direitos fundamentais, presentes no federalismo das federações e na autonomia municipal, releva a importância dessas reflexões, também para um melhor entendimento da própria federação brasileira.

\section{0 federalismo e a Federação brasileira}

O estudo do federalismo e das federações adentra no estudo da estruturação do poder na espacialidade estatal, uma vez que se trata de instrumentos de organização e distribuição do próprio poder. Federalismo e federação são termos que possuem uma mesma origem bíblica, relacionada à ideia de ligação entre Deus e os homens, e desses últimos entre si. A etimologia advém da palavra latina foedos, largamente usada pelo Império Romano, que significa compromisso, pacto, acordo, que na sua concepção política denota a união de pessoas, grupos ou entes na busca de objetivos comuns, sem deixar de resguardar a integridade das respectivas partes. A palavra federalismo surge no século XVI, com uso estritamente político a partir do século XVIII (ELAZAR, 1991, p. 5 e 268).
Não obstante, esta imbricação léxica e a confusão conceitual precipuamente nos séculos XVIII e XIX ${ }_{1}^{1}$ federalismo e federação são termos atualmente distintos que explicam fenômenos diferenciados, porém, interligados:

It is essential to begin by distinguishing between federalism and federation. Federalism is here construed as some form of doctrine - even a variety of these. [...] Federalism as a coherent and inclusive view of the world - at once philosophical, legal, anthropological, sociological, economic and political, a doctrine supposedly providing a sound basis for not only understanding but also directing the affairs of the world. [...] such federalism is to be a distinguished from federation, understood as a more limited institutional arrangement [...] federalism is some one or several varieties of political philosophy or ideology, and the federation is some type of political institution $^{2}$ (KING, 1982, p. 74-75).

Maurice Croisat segue na mesma esteira quando afirma que "le terme fédéralisme dans cette perspective ne concerne que les idées, les valeurs, les conceptions du monde, que expriment 'une philosophie compréhensive de la diversité dans l'únité'", ${ }^{3}$ enquanto federação "ce terme renvoi aux applications concrètes du fédéralisme" ${ }^{\prime 4}$ (1992, p. 15-16).

Assim, inúmeras são as formas nas quais o federalismo pode se expressar numa realidade fática - confederações, federações, arranjos federais, uniões, consociações, arranjos federais assimétricos, ligas, dentre outras -, entretanto, a busca da unidade na diversidade, com maior ou menor intensidade para um dos polos, encontra-se sempre presente. (ELAZAR, 1991, p. 38-66). 
Não é sem razão que o federalismo foi alvo de estudos de grandes expoentes do pensamento universal do século XVII ao XIX, como Johannes Althusius e a sua compreensão dos pactos como essenciais para o desenvolvimento humano, a adentrar na organização política, influenciado que foi pela Confederação Helvética e pela União de Províncias Suíças (GALVES, 1996, p. 142; ELAZAR, 1991, p. 139; CROISAT, 1992, p. 13); John Locke (2014) e o poder federativo como um poder de império natural do Estado (DEL VECCHIO, 1959, p. 130-133; GALVES, 1996, p. 145-148; BITTAR, 2001, p. 226227; ELAZAR, 1991, p. 141; NADER, 2001, p. 135-136; MORBIDELLI, 1999, p. 25); Montesquieu (2002, p. 141-142) e a consideração do federalismo como uma forma de governo indissociável da república; James Madison, Alexander Madison e John Jay (1959) em 85 artigos na defesa da proposta de Federação americana construída na Convenção da Filadélfia, o que foi ratificado pelos respectivos Estados; Immanuel Kant (1995) e a consideração do federalismo como um fim natural e imamente ao ser humano, com a paz perpétua a ser alcançada com uma federação de estados; Pierre Joseph Proudhon (2001) e a sua compreensão do federalismo como um princípio informador da sociedade, organizando-a em todas as áreas, capaz de harmonizar a eterna dialética entre a autoridade e a liberdade, a opor-se firmemente à hierarquia e à centralização; Michael Bakunin (1980, p. 113-114), que defende uma federação entre os estados europeus a fim de alcançar a paz, a liberdade e a justiça.

No campo da aplicação prática, ou seja, nas espacialidades nas quais o federalismo se concretizou, seja em protofederações, seja como confederações, podem-se citar as tribos de Israel, no século XIIIa.C., as ligas entre as cidades-estados da Grécia antiga, as ligas entre as cidades-estados do norte europeu entre os séculos XII e XVI, a Confederação Suíça na Europa Central, nos séculos XIII e XIX, as Províncias Unidas dos Países Baixos, nos séculos XVI e XVIII; apenas para constar exemplos históricos de maior relevo para o mundo ocidental (ELAZAR, 1991, p. 117-120; ZIMMERMANN, 1999, p. 217-219; PROUDHON, 2001, p. 107).

Naturalmente, não há como discorrer sobre o federalismo e as federações sem observar o modelo que mais influenciou os últimos séculos, qual seja, o modelo norte-americano, o primeiro estado federal moderno. Da Confederação forjada em 1776, com a independência, para uma Federação elaborada em 1787, calcada numa Constituição formal, republicana, sintética e liberal, com a explicitação clara das competências expressas da União e da competência residual aos Estados como forma de evitar o agigantamento federal (TOCQUEVILLE, 1998, p. 94; ZIMMERMANN, 1999, p. 248-251).

Várias questões alicerçaram o Estado Federal norte-americano, essenciais à Ciência Política e ao Direito, como a supremacia da Constituição sobre todas as demais leis e os atos de todos os poderes constituídos; a limitação das competências da União, para evitar a sua sobreposição aos Estados, com a definição de competências expressas das quais não pode se afastar; a forma de governo republicano, com mandatos limitados, sem privilégios a quem quer que seja, nem ao Presidente dos Estados Unidos, passí- 
vel de julgamento pelo Poder Judiciário e de destituição; e a independência do Poder Judiciário para a proteção da Constituição (HAMILTON, 1959; MADISON, 1959).

No Brasil, a saturação do regime monárquico, no decorrer do século XIX, acarretou o surgimento da Federação, sob a influência do modelo norte-americano, com rígida e dual separação de competências entre a União e os Estados, o que acabou por fortalecer as oligarquias regionais e as suas respectivas diferenças, sem olvidar, paradoxalmente, a influência do pensamento político francês (BONAVIDES, 1996, p. 170172; ZIMMERMANN, 1999, p. 310; PINTO FILHO, 2000, p. 103; HORTA, 1958, p, 26; CORRALO, 2006, p. 143-146).

A Federação acompanhou o desenvolvimento da república brasileira, presente em todas as Constituições republicanas, o que se observa em 1891, 1934, 1937, 1946, 1967 e 1988. Mesmo diante da perversidade do concentracionismo regional da primeira república ou do incomparável período ditatorial do Estado Novo, desnaturadores do próprio federalismo, as constituições que ampararam esses períodos históricos (1891 e 1937) mantinham a condição de um Estado republicano e federal, ao menos no papel. Em avanços e retrocessos, chega-se à Constituição de 1988, sem sombra de dúvidas, o mais avançado texto constitucional quando se tem por foco o Estado Federal e os direitos fundamentais da pessoa humana.

Não obstante as diferenças existentes entre os modelos de estados federais, surgidos nos séculos XIX e XX, decorrentes das particularidades e singularidades históricas, políticas, econômicas, culturais e sociais de cada Estado (BARTHALAY, 1981, p. 7; MORBIDELLI, 1999, p. 36-37; MIRANDA, 2002, p. 313; ELAZAR, 1991, p. 12, 27 e 39; BASTOS, 1985, p. 40; KUGELMAN, 2001, p. 33), deve-se salientar que as federações consubstanciam, com intensidade máxima, a busca da unidade na diversidade, foco maior do federalismo. Assim, é possível apresentar as seguintes características comuns às federações: a) Constituição escrita que define as competências da União e dos demais entes federados, além das situações excepcionais possibilitadoras de intervenção; b) pluralidade de esferas governamentais e ordens jurídicas; c) participação dos entes federados na construção da vontade nacional; d) órgão judicial para a defesa da Constituição; e) vedação de secessão (CORRALO, 2006, p. 142).

\section{A autonomia do município na Federação brasileira e a sua consideração como ente federado: 0 poder municipal}

A história do município brasileiro não surge com a República Federativa do Brasil. Por óbvio, é muito anterior. Remonta ao período da colonização portuguesa, do século XVI ao início do século XIX, com base nas Ordenações da Coroa Portuguesa, que vigoraram até a independência nacional. Nesse período, as Câmaras de Vereadores eram o centro da vida política local, a desfrutar as municipalidades, de considerável autonomia nos dois primeiros séculos da dominação lusitana, o que mudou radicalmente no final do século XVII, com a submissão das municipalidades aos governadores. Tal quadro, de parca autonomia, não muda com a primeira Constituição brasileira, 
pós-independência - de 1824 - a fortalecer um quadro de tutela dos municípios com as províncias (CORRALO, 2008, p. 11-17; D'AQUINO, 1940; MONTORO, 1975, p. 29; XAVIER, 1950, p. 121; PAUPÉRIO, 1959, p. 52; SOARES, 1986, p. 8).

Castro Nunes sintetiza essa condição municipal em obra do início do século XX:

Vê-se que no Brasil nunca chegamos a ter o self-government municipal. Toda a nossa evolução política se fez em torno das províncias. No Brasil-Colônia, como no Brasil-Reino, a instituição municipal era planta exótica que nunca chegou a crear fundas raízes no solo brasileiro. E tanto é isso exacto que, fundado o Império Constitucional, a lei de 1828 deu às municipalidades uma organização em contraste flagrante com o ainda tão próximo passado colonial: as Comunas reduzidas a corporações meramente administrativas "meras peças da vasta engrenagem da administração geral do Império" (1920, p. 49).

A proclamação da República e a construção do Estado Federal brasileiro não alteraram significativamente a condição municipal, pois remeteram aos estados-membros a disciplina da organização municipal, atrelada aos interesses das oligarquias dominantes em cada região, também denominadas de coronelismo. Era o que dispunha a Constituição de 1891. O município continuava a ser compreendido como uma instância meramente administrativa (PAUPÉRIO, 1959, p. 20; BARBOSA, 1947, p. 120; MONTORO, 1975, p. 41; SANTIN, 2007, p. 72-78).

A reforma constitucional de 1926 elevou a autonomia municipal à condição de princípio possibilitador da intervenção da União nos Estados que não o observavam. Entretanto, essa ordem constitucional não perdurou por muito tempo, substituída pelo Decreto 19.398, de 1930, resultado da vitória do movimento revolucionário que chegou ao poder com Getúlio Vargas. A concentração de poder foi gigantesca, a fulminar até mesmo com a eletividade dos prefeitos. Nulificou-se, ainda mais, a autonomia dos municípios, sob a égide dos Conselhos Consultivos Municipais (CORRALO, 2006, p. 80; MONTORO, 1975, p. 46-47).

A Constituição de 1934 operou uma mudança significativa no status municipal, a resguardar uma mínima autonomia política, administrativa e financeira. Garantiu-se a eletividade de prefeitos e vereadores, salvo nas capitais e instâncias hidrominerais, possibilitando, também, a escolha do prefeito pelos vereadores; a arrecadação de tributos próprios; a auto-organização dos seus serviços naquilo que for pertinente ao peculiar interesse; e a intervenção nos Estados que não observassem a autonomia municipal. Essa Constituição significou um grande avanço para os municípios, obstaculizada pela sua vigência, não superior a 3 anos.

A ditadura comandada por Getúlio Vargas perdurou de 1937 a 1945 e significou um período marcado pela imposição da força, sob a égide da Constituição de 1937. O poder estava centralizado, mantendo os municípios sob o total controle do Departamento ou Conselho Administrativo e da Presidência da República. Os Prefeitos passaram a ser nomeados pelos interventores dos Estados. Dissipa-se a incipiente autonomia consagrada pela Constituição de 1934. Desnatura-se a própria Federação pelas trevas de um centralismo sem comparação na história republicana (CORRALO, 2006, p. 79-84). 
A Constituição de 1946 retomou a esteira da Constituição de 1934, reforçou a autonomia dos municípios e foi além. Também trouxe a possibilidade, pela primeira vez na história, de intervenção dos Estados nos municípios, somente nas situações expressas no texto constitucional e trouxe a possibilidade de contração de dívidas no exterior, desde que previamente aprovadas pelo Senado da República. Esta Constituição resguardou, efetivamente, a autonomia política, administrativa, legislativa e financeira dos entes locais. (MONTORO, 1975, p. 56-60; DISESSA, 1951, p. 17, 217, CORRALO, 2006, p. 84-86).

A normalidade da ordem constitucional de 1946 foi rompida em 1964, com o Golpe Militar, do qual se seguiu o que se pode chamar Constituição de 1967. Por se tratar de um regime ditatorial, fragilizou-se a autonomia dos municípios, especialmente a autonomia política. Somente mais de duas décadas após, com a Constituição de 1988, retoma-se a tradição democrática e descentralizadora das constituições de 1934 e 1946.

A repartição de competências operada pela Constituição de 1988 fortalece as municipalidades. Ao lado das competências próprias da União (arts. 21 e 22 da Constituição) e da competência residual aos Estados (art. 25 da Constituição), convivem as competências concorrentes - União, Estados e Distrito Federal - e as competências comuns - pertencentes a todos os entes (arts. 24 e 23, respectivamente, da Constituição). Além dessas, o texto constitucional definiu competências expressas aos municípios, alicerçadas em tudo o que for pertinente ao interesse local (arts. 29 e 30 da Constituição). Isso sem olvidar as demais competências esposadas no decorrer do texto constitucional, uma vez que os arts. 21 a 30 traduzem a espinha dorsal que molda a repartição de competências entre os entes federados. (CORRALO, 2011, p. 50-54; ALMEIDA, 2002; MELO FILHO, 2000, p. 273).

É com base nas competências constitucionais que é possível compreender a autonomia dos municípios na Federação brasileira. Ao se decantar os dispositivos constitucionais atinentes às municipalidades, é possível compreender um plexo de cinco autonomias (CORRALO, 2006, p. 188214; CORRALO, 2011, p. 54-55):

a) autonomia auto-organizatória: é o poder dos municípios para a elaboração das suas Leis Orgânicas Municipais, nos termos do art. 29 da Constituição Federal, conformando sua organização, os poderes Executivo e Legislativo, as políticas públicas, dentre outras questões;

b) autonomia política: refere-se à eletividade do prefeito, vice-prefeito e vereadores pelos cidadãos, os dois primeiros em chapas por eleição majoritária, e os edis em eleição proporcional;

c) autonomia financeira: depreende-se da instituição dos tributos locais - impostos, contribuições e taxas -, como também da aplicação dos recursos provenientes das transferências constitucionais, o que ocorre via elaboração das leis orçamentárias. Nesse diapasão encontram-se, também, as transferências voluntárias, normalmente atreladas a projetos pré-definidos pela União ou pelo Estado; 
d) autonomia administrativa: denota a organização e a funcionalidade própria das atividades administrativas desenvolvidas pela municipalidade, como é o caso dos serviços públicos, da polícia administrativa, do fomento e da intervenção direta e indireta;

e) autonomia legislativa: é a possibilidade do município de elaborar o seu sistema normativo local, a seguir as espécies legislativas previstas no art. 59 da Constituição - aplicadas nos termos da Lei Orgânica, sujeitas ao controle de constitucionalidade.

A condição a que foram alçados os municípios pela Constituição de 1988 faz com que esses sejam considerados entes integrantes da federação brasileira, o que se encontra explícito nos arts. $1^{\circ}$ e 18 da Constituição Federal (CORRALO, 2006, p. 153-155; MORAES, 2002, p. 273-275; MEIRELLES, 1993, p. 39; COSTA, 1999, p. 73; RAMOS, 2000, p. 194; MORBIDELLI, 1999, p. 188; ZIMMERMANN, 1999, p. 343; LEWANDOWSKI, 1994, p. 24; MARIOTTI, 1999, p. 85-86; BASTOS, 1985, p. 40; FERRERI, 1995, p. 32; FERREIRA FILHO, 1997, p. 18; SANTIN; FLORES, 2006, p. 56-69). Essa situação é única nos estados federais contemporâneos, o que realça as singularidades da federação pátria.

É nesse contexto que exsurge um poder municipal, alicerçado na Constituição Federal, enquanto ente federado no exercício do plexo de autonomias extraídos da ordem constitucional. Um poder defendido e garantido pela ordem constitucional, cujo exercício resplandece o fortalecimento das localidades e da cidadania.

\section{Relações entre a autonomia municipal e o federalismo: 0 caso do Brasil}

As reflexões, neste tópico, são efetuadas em duas perspectivas. Primeira, demonstrar a ligação umbilical entre a autonomia municipal e o federalismo, numa perspectiva teórica. Segunda, a fim de comprovar a facticidade dessa ligação na ordem constitucional brasileira.

Afirmar que a autonomia municipal e o federalismo designam fenômenos teóricos complementares não significa afirmar, por óbvio, que todas as federações resguardam a autonomia municipal em alto grau, ou que os Estados federais possuem municípios mais autônomos que os Estados unitários. Pode-se, isso sim, dizer que os Estados federais tendem a resguardar em maior grau a autonomia local:

[...] o federalismo e a autonomia do poder local estão para si mesmos como duas faces de uma mesma moeda, se complementando na formação de uma realidade teoricamente interdependente (CORRALO, 2006b, p. 192).

Isso porque o federalismo, nas federações, engloba um feixe de princípios informadores: Estado constitucional democrático, república, não centralização, subsidiariedade, pluralismo e liberdade. Esses princípios também embasam um poder municipal autônomo, que sustenta o plexo de autonomias gozadas pelos municípios brasileiros: auto-organizatória, política, administrativa, financeira e legislativa.

Ao se apreender as federações como a aplicação fática do federalismo e seus princípios informadores com o máximo de inten- 
sidade, o princípio do Estado constitucional democrático demonstra-se essencial, pois as federações requerem um marco constitucional, sem o qual não restam repartidas as competências entre os entes integrantes, como também um regime democrático. Num Estado ditatorial, solapa-se a federação, o que se entrelaça com o princípio da liberdade, que afirma o espaço da individualidade e dos grupos sociais (ELAZAR, 1991, p. 34, 87-136; CANOTILHO, 1999, p. 224-225; HOWARD, 1996, p. 11-26). No mesmo sentido, a república, amplamente refletida e defendida nos textos de The Federalist, aparece como um "remédio republicano para doenças republicanas", no combate aos privilégios, no controle do poder pela sua derivação popular e na limitação do seu exercício. Por mais que seja possível pensar uma monarquia constitucional federal (DALLARI, 1986, p. 28), república e federalismo complementam-se principiologicamente e teleologicamente (HAMILTON; MADISON; JAY, 1959). O princípio da não centralização é conflitante com o centralismo e a centralização, significando um fenômeno distinto da descentralização, pois alicerçada na existência de um poder difuso, policêntrico, sem o controle de um poder central (OSTROM, 1991, p. 227; BALDI, 2001, p. 9; RAMOS, 2000, p. 40-41). A subsidiariedade se entrelaça nesse rol principiológico, reforçando-o a limitar a atuação dos entes mais distantes, quando passível a atuação dos entes mais próximos da população (BARACHO, 2000, p. 46; ZIMMERMANN, 1999, p. 200203). Por fim, o pluralismo vai significar a afirmação da diversidade, na ideia da multiplicidade dos possíveis, contrapondo-se às construções unitárias, centralizadoras e homogêneas (BALDI, 2001, p. 9-2- ; WOLKMER, 1997, p. 155-162; ELAZAR, 1991, p. 8791; CROISAT, 1992, p. 24).

Há um entrelaçamento e uma complementariedade entre a autonomia municipal e os princípios informadores do federalismo, a reportar uma relação diretamente proporcional, pois o acréscimo da autonomia municipal redunda no fortalecimento dos princípios do federalismo, da mesma forma que o fortalecimento dos princípios do federalismo conduz a uma maior autonomia municipal.

Nesse mesmo sentido, conforme Dircêo Torrecillas Ramos,

[...] o sucesso depende de interação, da cooperação intergovernamental com o compromisso de autonomia local, a responsabilidade de controle local e a manutenção da integridade do Estado-Membro como um copo político" (2000, p. 45).

A autonomia dos municípios é essencial para a federação brasileira, a ponto de poder sustentar, na federação brasileira, a autonomia municipal como uma norma de direito fundamental (CORRALO, 2006b, p. 253-262).

Como se manifestou Pierre-Joseph Proudhon, o contrato de federação "[...] consiste em reservar sempre mais para os cidadãos que para o Estado, para as autoridades municipais e provinciais que para a autoridade central [...]" (2001, p, 98), ou seja, salienta o relevo das instâncias mais próximas do cidadão, "the spirit of federals"5 (ELAZAR, 1991, p. 188), razão pela qual os estados totalitários ou ditatoriais acabam com a autonomia local, pois antitéticos ao federalismo (GAGLIANO, 1978, p. 42). 
O plexo de autonomias gozadas pelos municípios brasileiros se apoia nos princípios do federalismo que conformam a federação pátria e que refletem o disposto no texto constitucional. Por óbvio, não significa que todas as federações refletem esse mesmo conjunto de autonomias municipais consagradas pela Constituição brasileira de 1988. Denota, isso, sim, a compatibilidade dos princípios do federalismo em estados federais com a autonomia municipal, numa perspectiva teórica, bem como a facticidade dessa compatibilidade quando se tem por foco de análise o caso brasileiro.

\section{Considerações finais}

Com base nas reflexões feitas neste artigo, é possível chegar às seguintes conclusões:

I - Federalismo e federação são termos distintos, porém, no decorrer da maior parte da história humana foram tratados como sinônimos. É a partir do século XX que se compreende o federalismo como um conjunto de princípios e ideias que buscam a unidade na diversidade, aplicando-se de diversas formas na realidade fática, na qual a federação é uma das possibilidades.

II - As federações acabam por aplicar, com intensidade máxima, os princípios e ideais do federalismo numa espacialidade estatal. O relevo do federalismo e das federações faz com que, há mais de 2 mil anos, existam relatos da sua aplicação fática, associado a importantes refle- xões que têm sido produzidas nos últimos quatro séculos.

III -O Brasil adotou o modelo de Estado Federal com a República, concretizado na Constituição de 1891, nos moldes do federalismo dual norte-americano. No decorrer do século $\mathrm{XX}$, as constituições mantiveram esse modelo, mesmo quando a realidade ditatorial e concentracionista a desnaturaram.

IV- O Brasil, com a Constituição de 1988, foi a única Federação a alçar as municipalidades à condição de entes federados. Depreendido da repartição de competências operada no texto constitucional, é possível compreender um plexo de autonomias aos municípios: auto-organizatória, política, legislativa, financeira e administrativa. Isso permite aceitar a existência de um verdadeiro poder municipal.

$\mathrm{V}$ - Autonomia municipal e federalismo estão teoricamente interligados, como duas faces de uma mesma moeda. Os princípios que informam o federalismo - Estado constitucional democrático, república, não centralização, subsidiariedade, pluralismo e liberdade -entrecruzam-se com a autonomia municipal.

VI-É possível afirmar que o entrelaçamento e a complementariedade entre a autonomia municipal e os princípios informadores do federalismo, numa relação diretamente proporcional, são enfatizados pela posição ocupada pelo município brasileiro na federação. 


\section{Abstract}

The goal of this work is to study the municipal power in the Brazilian Federation, namely the relation between the municipal self-government and the federalism. Far from persecute purity methodological, the methodology of this work is dialectical. Therefore, the chapter in sequence studies the federalism and the Brazilian Federation, theoretically and historically. In addition, one studies the municipal autonomy in the Brazilian Federation and your position as federal ente. Lastly, the chapter in sequence deals the relation between the municipal self-government and the federalism, in a theoretical way and the situation in the Brazilian constitutional reality. The conclusion points out the relation between the municipal autonomy and the federalism.

Keywords: Municipal Self -government. Federalism. Brazilian federation.

\section{Resumen}

El artículo tiene la meta de estudiar el poder municipal en la federación brasileña con atención para la autonomía municipal y federalismo. Lejos de tener pureza metodológica, el método dialéctico es utilizado en la elaboración deste trabajo científico. Asi, hay el estudio teorético y histórico sobre el federalismo y la federación brasileña. En secuencia se hace la reflexión sobre el município en la federación e su consideración como ente federado. Por fin, se piensa en la relación entre la autonomía municipal y federalis- mo, teóricamente y en su facticidad en el constitucionalismo del Estado brasileño. La conclusión es de la relación entre el federalismo y la autonomia municipal.

Palabras claves: Autonomía municipal. Federalismo. Federación brasileña.

\section{Notas}

1 Podem-se observar as obras de Monstesquieu (2002, p. 143-144) e os textos de The Federalist, construídos por James Madison, Alexander Madison e John Jay, que não distinguem Estado federal e confederal e nem avançam, por óbvio, na diferenciação de federalismo e das suas aplicações fáticas em determinados territórios das quais exsurgem as federações, confederações e outras formas (OSTROM, 1991, p. 7).

2 “É essencial começar pela distinção entre federalismo e federação. Federalismo é aqui considerado como uma forma de doutrina - uma variedade destas. [...] Federalismo como uma coerente e abrangente visão do mundo - filosófica, legal, antropológica, sociológica, econômica e política, uma doutrina supostamente provedora de uma base profunda não somente para a compreensão, mas também direcionada para as questões do mundo [...] tal federalismo é distinto de federação, entendida como um arranjo institucional limitado [...] federalismo é alguma ou muitas variedades de filosofias políticas ou ideologias, e a federação é algum tipo de instituição política" (tradução nossa).

3 "o termo federalismo numa certa perspectiva não se refere senão às ideias, aos valores, às concepções de mundo que exprime 'uma filosofia compreensiva da diversidade na unidade'" (tradução nossa).

4 "este termo refere-se às aplicações concretas do federalismo" (tradução nossa).

5 "o espírito do federalismo" (tradução nossa). 


\section{Referências}

ALMEIDA, Fernanda Dias Menezes. Competências na Constituição de 1988. São Paulo: Atlas, 2002.

BALDI, Brunetta. Stato e Territorio: federalismo e decentramento nelle democrazie contemporanee. Roma: Laterza, 2003.

BARBOSA, Rui. A Imprensa. Obras Completas de Rui Barbosa. Rio de Janeiro: Imprensa Nacional, 1947. t. I, v. XXV.

BASTOS, Celso. A Federação no Brasil. Brasília: Instituto dos Advogados de São Paulo, 1985.

BARACHO, José Alfredo de Oliveira. Teoria Geral do Federalismo. Rio de Janeiro: Forense, 1986.

. O Princípio da Subsidiariedade: conceito e evolução. Rio de Janeiro: Forense, 2000.

BARTHALAY, Bernard. Le Federalisme. Paris: Presses Universitaires de France, 1991.

BAKUNIN, Michael Alexandrovich. Textos Anarquistas. Porto Alegre: L e PM Pocket, 1980.

BITTAR, Eduardo; ALMEIDA, Guilherme. Curso de Filosofia do Direito. São Paulo: Atlas, 2001.

BONAVIDES, Paulo. A Constituição Aberta: temas políticos e constitucionais da atualidade, com ênfase no Federalismo das Regiões. São Paulo: Malheiros, 1996.

CANOTILHO, Joaquim Gomes. Direito Constitucional e Teoria da Constituição. Coimbra: Almedina, 1999.

COSTA, Nelson Nery. Curso de Direito Municipal Brasileiro. Rio de Janeiro: Forense, 1999.

CORRALO, Giovani da Silva. Município: autonomia na Federação brasileira. Curitiba: Juruá, 2006.

. A Autonomia Municipal como um Direito Fundamental na Constituição Brasileira. 2006. Tese (Doutorado em Direito), Programa de Pós-Graduação em Direito, Universidade Federal do Paraná/UFPR. Curitiba, 2006.
Atlas, 2011.

Curso de Direito Municipal. São Paulo:

CROISAT, Maurice. Le Fédéralisme dans les Démocraties Contemporaines. Paris: Montchrestien, 1992.

D’AQUINO, Ivo. O Município: sua conceituação histórica e jurídico-constitucional. Florianópolis: Imprensa Oficial do Estado de Santa Catarina, 1940.

DALLARI, Dalmo de Abreu. O Estado Federal. São Paulo: Ática, 1986.

DISESSA, Orestes Bianco. Autonomia Municipal: cláusula de peculiar interesse. São Paulo: Revista dos Tribunais, 1951.

ELAZAR, Daniel. Exploring Federalism. Tuscaloosa: The University of Alabama Press, 1991.

FERREIRA FILHO, Manoel Gonçalves. Comentários à Constituição Brasileira de 1988. São Paulo: Saraiva, 1997.

GAGLIANO, Diana. Enfoque Federalista para la Sociedad em Crisis. Buenos Aires: Ediciones Depalma, 1978.

GALVES, Carlos Nicolau. Manual de Filosofia do Direito. Rio de Janeiro: Forense, 1996.

HAMILTON, Alexander; JAY, John; MADISON, James. O Federalista. Rio de Janeiro: Editora Nacional de Direito, 1959.

HORTA, Raul Machado et al. Problemas Gerais do Federalismo. In: HORTA, Raul Machado. Perspectivas do Federalismo Brasileiro. Belo Horizonte: Universidade de Minas Gerais, 1958.

KANT, Immanuel. A Paz Perpétua e Outros Opúsculos. Lisboa: Edições 70, 1995.

KING, Preston. Federalism and Federation. Baltimore: The Johns Hopkins University Press, 1982.

KUGELMAS, Eduardo. A Evolução Recente do Regime Federativo no Brasil. In: HOFMEISTER, Wilhelm; CARNEIRO, José Mário (Org.). Federalismo na Alemanha e no Brasil. São Paulo: Konrad Hesse, 2001. (Série debates, n. 22, v. I). 
LOCKE, John. Second Treatise of Government. Indianopolis: Hackett Publishing Company, 1980. Disponível em: <http://www.gutenberg.org/files/7370/7370-h/7370-h.htm>. Acesso em: 2 maio 2014.

LEWANDOWSKI, Enrique Ricardo. Pressupostos Materiais e Formais da Intervenção Federal no Brasil. São Paulo: Revista dos Tribunais, 1994.

MARIOTTI, Alexandre. Teoria do Estado. Porto Alegre: Síntese, 1999.

MELO FILHO, Urbano Vitalino. Perspectivas dos Municípios na Federação Brasileira. In: BASTOS, Evandro de; GORBES JÚNIOR, Odilon (Org.). Novos Rumos da Autonomia Municipal. São Paulo: Max Limonad, 2000.

MIRANDA, Jorge. Teoria do Estado e da Constituição. Rio de Janeiro: Forense, 2002.

MONTESQUIEU. Do Espírito das Leis. São Paulo: Martin Claret, 2002.

MONTORO, Eugênio Franco. O Município na Constituição Brasileira. São Paulo: Universidade Católica, 1945.

MORAES, Alexandre. Direito Constitucional. São Paulo: Atlas, 2002.

MORBIDELLI, Janice Helena Ferreri. Um Novo Pacto Federativo para o Brasil. São Paulo: Celso Bastos Editor, 1999.

NADER, Paulo. Filosofia do Direito. Rio de Janeiro: Forense, 2001.

NUNES, José de Castro. Do Estado Federado e sua Organização Municipal. Rio de Janeiro: Leite Ribeiro e Maurillo, 1920.

OSTROM, Vincent. The Meaning of American Federalism: constituting a self-governing society. San Francisco: Institute for Contemporary Studies, 1991.

PAUPÉRIO, Arthur Machado. O Município e seu Regime Jurídico no Brasil. Rio de Janeiro: Forense, 1959.
PINTO FILHO, Francisco Bilac. A Intervenção Federal e o Federalismo Assimétrico. Rio de Janeiro: Forense, 2002.

PROUDHON, Pierre Joseph. Do Princípio Federativo. São Paulo: Imaginário, 2001.

RAMOS, Dircêo Torrecillas. O Federalismo Assimétrico. Rio de Janeiro: Forense, 2000.

SANTIN, Janaína Rigo; FLORES, Deborah Hartmann. A Evolução Histórica do Município no Federalismo Brasileiro, o Poder Local e o Estatuto da Cidade. Justiça do Direito (UPF), Passo Fundo, v. 20, n. 1, p. 56-69, 2006.

SANTIN, Janaína Rigo. O Tratamento Histórico do Poder Local no Brasil e a Gestão Democrática Municipal. Estudos Jurídicos (Unisinos), v. 40, p. 72-78, 2007.

SOARES, Antônio Carlos Otoni. A Instituição Municipal no Brasil. São Paulo: Revista dos Tribunais, 1986.

TOCQUEVILLE, Aléxis. A Democracia na América. Belo Horizonte: Itatiaia Limitada, 1998.

VECCHIO, Giorgio Del. Lições de Filosofia do Direito. Coimbra: Américo Amado Editor, 1959.

ZIMMERMANN, Augusto. Teoria Geral do Federalismo Democrático. Rio de Janeiro: Lúmen Juris, 1999.

XAVIER, Rafael. Campanha Municipalista. Rio de Janeiro: IBGE, 1950.

WOLKMER, Antônio Carlos. Pluralismo Jurídico: fundamentos de uma nova cultura no direito. São Paulo: Alfa Omega, 1997. 